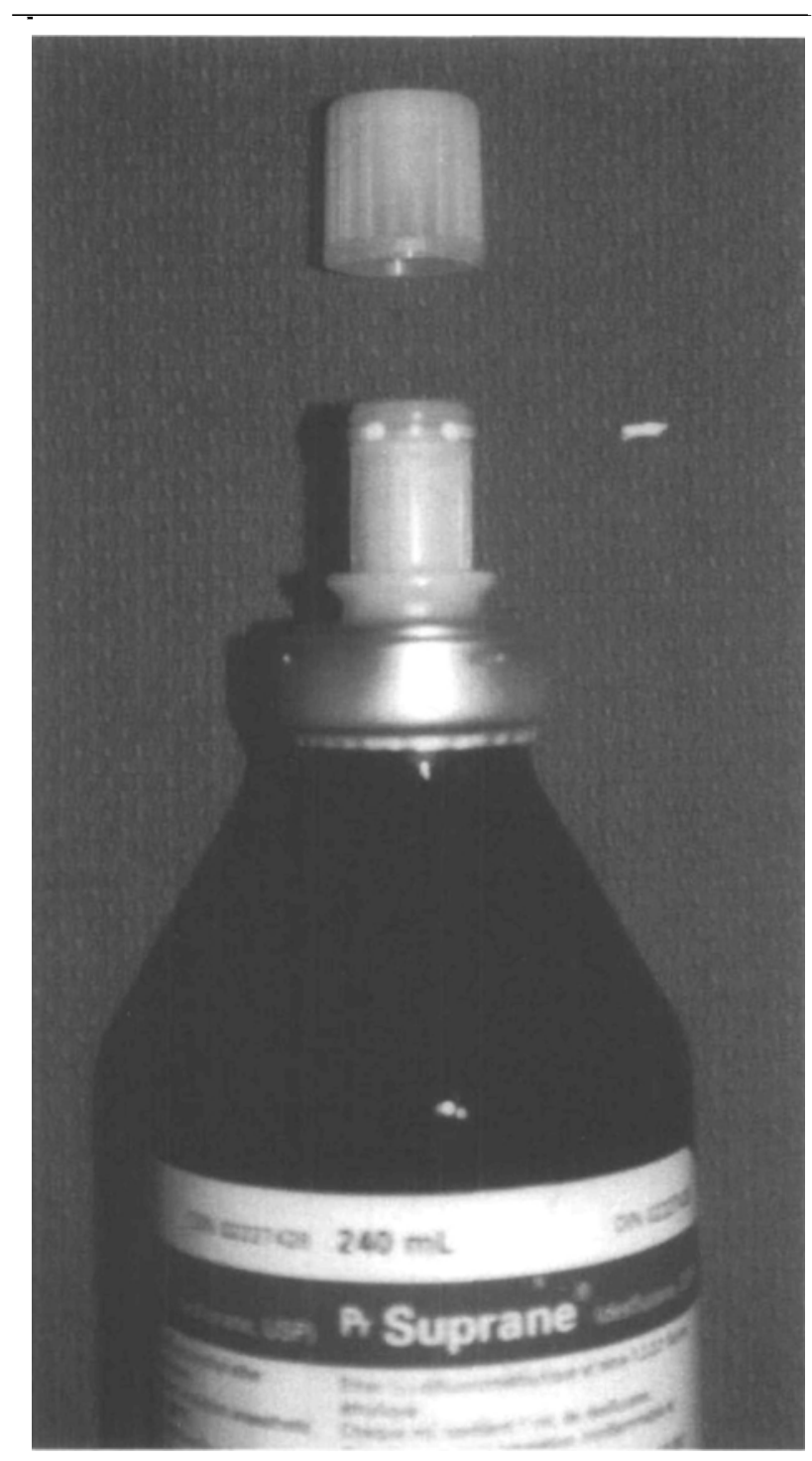

FIGURE Suprane (Desflurane) refill bottle demonstrating the damaged "O" ring of the SAF-T-FILI ${ }^{\text {TM }}$ bayonet firment.

We do not recommend that anesthesia practitioners replace torn or damaged $O$-rings. This practice could lead potentially to personal injury, contamination of the drug product, or release of anesthetic agent into the operating room environment. Suprane(B) bottles with damaged $O$-rings may be returned to the local distributor for replacement or proper credit.

Stephen Cunningham MD FRCP FFPM

Director, Clinical and Medical Affairs

Zeneca Pharma Inc.

Mississauga, Ontario

\section{Reflex sympathetic dystrophy}

To the Editor:

The editorial on RSD by Dr. Richard Catchlove in the September issue of this Journal ${ }^{1}$ was disappointing. While I agree with his comment on nomenclature, (we both prefer the term reflex sympathetic dystrophy over complex regional pain syndrome), his emphasis on psychosocial factors in the etiology of this pain state was disappointing.

While psychosocial factors have adverse impacts on most disease states, e.g. nutrition, COPD, dyspepsia and cardiovascular disease, we now know that more specific knowledge of underlying pathophysiology permits better, more effective trearment modalities, as in asthma and peptic ulcer disease (both at one time thought to be "psychogenic" disease states). Currently data from genetics, ${ }^{2}$ neuroanatomy ${ }^{3}$ and neurophysiol$\mathrm{ogy}^{4}$ indicate new and better directions for investigation and treatment of this pain state as did the research article by Otake $e t a l .{ }^{5}$ published in the same issue.

As for "psychogenic pain" readers of this journal should know that of the three authors who first published on this issue, Harold Merskey, Richard Sternbach and Wilbert Fordyce, the two former no longer believe in this entity. Dr Merskey has publicly stated that pain formerly thought to be psychogenic most likely is due to organic/neurophysiological processes.

Ellen N. Thompson MB BS FRCPC

Ottawa, Ontario

\section{References}

1 Catchlove R. Reflex sympathetic dystrophy (Editorial). Can J Anaesth 1998; 45: 829-30.

2 Mailis A, Wade J. Profile of Caucasian women with possible genetic predisposition to reflex sympathetic dysrophy: a pilot study. Clin J Pain 1994; 10: 210-7.

3 Groen GJ, Baljet B, Drukker J. Nerves and nerve plexuses of the human vertebral column. American Journal of Anatomy 1990; 188: 282-96.

4 Campbell $J N$. Complex regional pain syndrome and the nervous system. An updated review. Pain, IASP Press, 1996: 89-96.

5 Otake $T$, Ieshima $H$, Ishida $H$, Ushigome $\Upsilon$, Saito $S$. Bonc atrophy in complex regional pain syndrome patients measured by microdensitometry. Can J Anaesth 1998; 45: 831-8. 
A

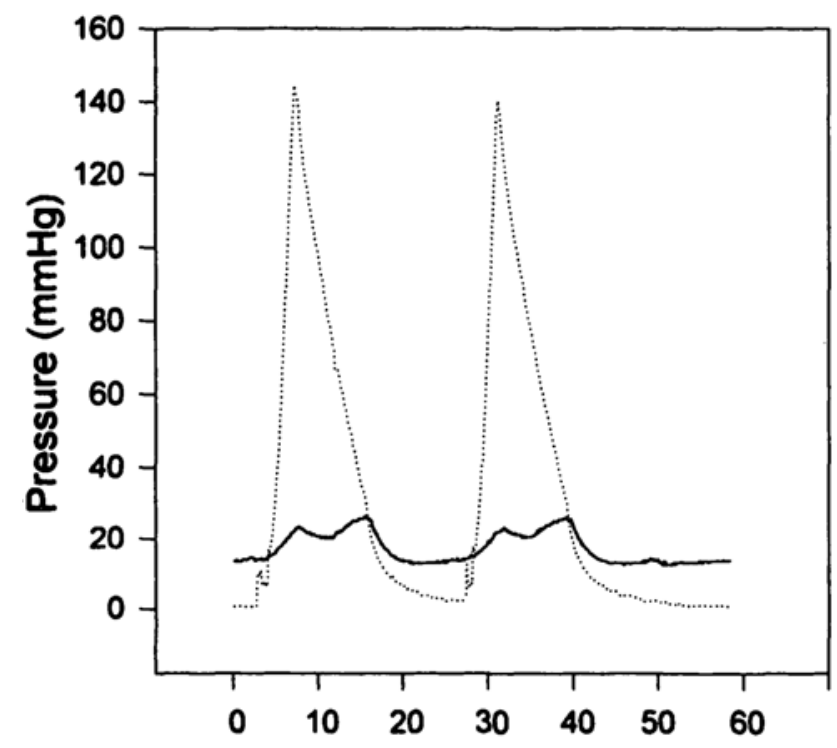

B

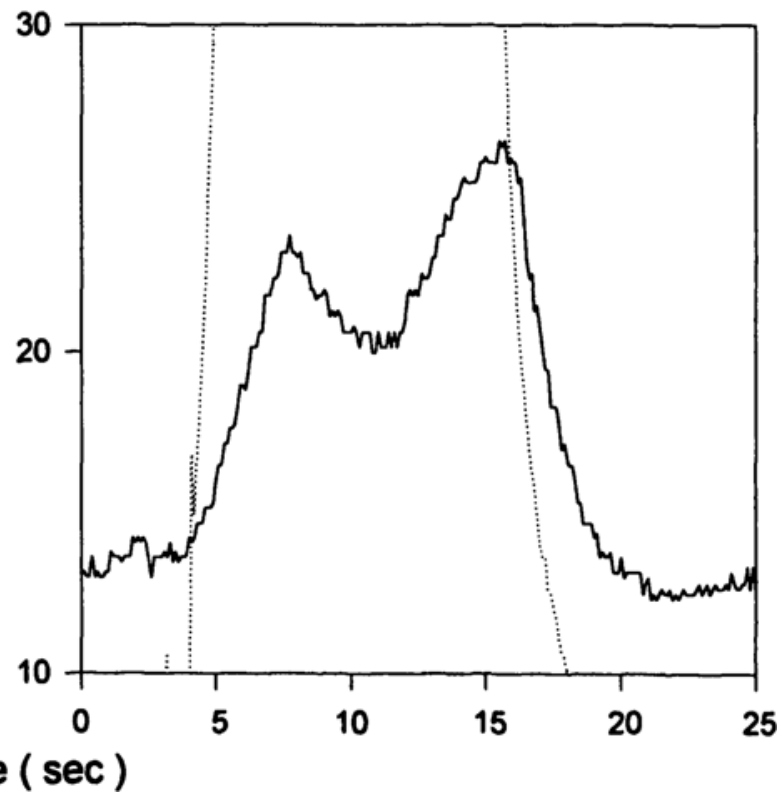

FIGURE Typical peripheral venous pressure change during NIBP monitoring. (A) Gross change in the two traces of venous pressure and cuff pressure waveform is shown. (B) Boxed area in Figure was magnified. Note that venouse pressure change is biphasic during NIBP measurement. Second peak was higher than the first peak with a notched area between.

\section{The peripheral venous pressure changes during non-invasive blood pressure measurement}

To the Editor:

Venous backflow into the infusion line and resultant occlusion can frequently occur during noninvasive blood pressure (NIBP) measurement The methods employed to counteract increase in peripheral venous pressure (PVP) include elevating the iv solution bag, routing the infusion tubing through the $\mathrm{BP}$ cuff so that it is sandwiched between the Velcro layers, ${ }^{1,2}$ or placing a check valve within the iv tubing, etc. However, these methods are used empirically without any experimental background on the change in the PVP. In this study we tried to obtain the pattern and range of PVP change during NIBP measurement before and during enflurane anesthesia.

PVP waveforms during NIBP measurement were recorded from six subjects., and PVPs were measured and compared before induction and at $30 \mathrm{~min}$ after induction of enflurane anesthesia (n7-19).

As a result, PVP change was biphasic in shape during NIBP monitoring (Figure). Second peak, which occurs during deflation period, was always higher than the first peak. Range of peak PVP was $12-130 \mathrm{mmHg}$ ( $57 \pm 3 \mathrm{mmHg}$, mean \pm S.E.) and PVP change was augmented during enflurane anesthesia $(32.9 \pm 2.9$ $\mathrm{mmHg}$ before anesthesia vs $70.4 \pm 5.4 \mathrm{mmHg}$ after anesthesia; $P<0.05$ ).

In conclusion, we found that peripheral venous pressure during NIBP measurement peaks at deflation phase, and the range of the PVP change is augmented by enflurane anesthesia. These patterns and the range of PVP change should be kept in mind when we apply methods to counteract venous regurgitation during NIBP monitoring.

\section{J.Y. Sim MD \\ Y. Choi MD \\ M.J. Yoon MD \\ D.M. Lee MD \\ J.W. Leem PhD \\ Seoul, Korea}

\section{References}

1 Wait CM. Blood pressure measurements and intravenous infusions (Letter). Anaesthesia 1992; 47: 1012. 